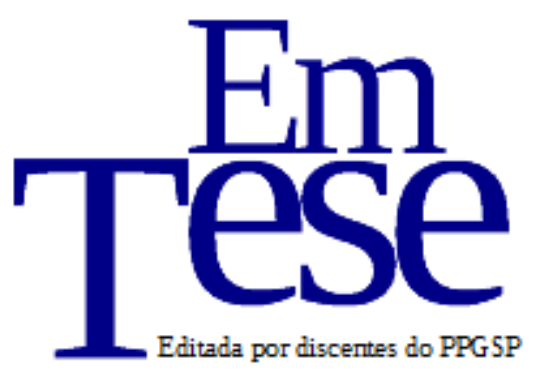

UFSC

PPG SP PROG RAMA DE

PÓS-GRADUAÇÃO EM

Sociologia

Política

v. 14, n. 1, jan./jun., 2017

\title{
José de Alencar e o tema da participação feminina no Brasil do século XIX: nuances conceituais
}

David Simões ${ }^{1}$

\begin{abstract}
Resumo: O artigo discute o tema da participação feminina no Brasil do século XIX a partir de dois escritos de José de Alencar (1829-1877): Uma tese constitucional: A Princesa Imperial e o Príncipe Consorte no Conselho de Estado (1867) e Sistema representativo (1868). Esses escritos apontam para um olhar tutelar a respeito da participação feminina que pode referir-se a dois sentidos, respectivamente: o da incapacidade política da mulher, pura e simplesmente, ou então, o que parece ser mais curioso, o do reconhecimento da inexistência política dessa categoria como problema a ser pensado. Como será demonstrado, na tentativa de resolver o dilema da inclusão das mulheres na composição do corpo político, Alencar propôs nesse último escrito, uma via conceitual caracteristicamente sua, que alia, numa mesma matriz, elementos aparentemente contraditórios, quais sejam: participação e tutela.
\end{abstract}

Palavras Chave: José de Alencar. Participação Feminina. Pensamento Conservador.

\begin{abstract}
The article discusses the theme of female participation in nineteenth-century Brazil from two writings of José de Alencar (1829-1877): Uma tese constitucional: A Princesa Imperial e o Príncipe Consorte no Conselho de Estado (1867) and Sistema representativo (1868). These writings point to a tutelary view of women's participation, but that can refer to two meanings: the pure and simple political incapacity of women, or, what seems to be more curious, the recognition of the political non-existence of this category as a problem to be thought. As will be demonstrated, attempting to solve the dilemma of the inclusion of women in the composition of the political body, Alencar proposed an original conceptual matrix which combines apparently contradictory elements, which are: participation and tutelage.
\end{abstract}

Keywords: José de Alencar. Female Participation. Conservative Thought.

\footnotetext{
${ }^{1}$ Mestre em Sociologia (2012) pela Universidade Federal da Paraíba (UFPB). Professor do Colegiado de Ciências Sociais da Universidade Federal do Vale do São Francisco (UNIVASF).
} 


\section{Introdução}

Antônio Herculano Lopes (2010) já apontou que a temática sobre o papel da mulher na sociedade brasileira do século XIX foi discutida por José de Alencar (1829-1877) em sua obra teatral, entre os anos 1857 e 1859. Em artigo intitulado $O$ teatro de Alencar e a imaginação da sociedade brasileira, Lopes destaca a preocupação do romancista cearense com o processo de instauração, no Brasil, do modelo familiar burguês moderno, o qual se apresentava, ao mesmo tempo, desejável e ameaçador (LOPES, 2010, p. 90). Desejável por representar a própria modernidade e ameaçador por projetar o avanço da mulher nos espaços públicos.

O contexto da segunda metade dos oitocentos era favorável a esse avanço, principalmente, no maior centro urbano do Império, o Rio de Janeiro, que contava com um espaço civilizatório por excelência, a Rua do Ouvidor. Nesse mesmo sentido, Maria Ângela D’Incao (2000) afirma que, ao longo do século XIX, os centros urbanos ganham maior projeção como espaços favoráveis à constituição de novas formas de sociabilidade e comportamento. O próprio espaço doméstico passa por mudanças, tentando resguardar maior intimidade para os indivíduos que nele convivem. É no interior desse panorama que se dará "o nascimento de uma nova mulher nas relações da chamada família burguesa, agora marcada pela valorização da intimidade e da maternidade" (D’INCAO, 2000, p. 223).

Para Lopes, no caso de Alencar, tratava-se de "encarar os dilemas da família brasileira, num quadro de transição modernizadora, espremida entre a ordem escravocrata patriarcal e as promessas de um capitalismo nascente" (LOPES, 2010, p. 94). Assim, o teatro de Alencar seria uma tentativa de assimilação dos costumes modernos dentro de uma proposta de preservação de valores do modelo patriarcal da família brasileira. Daí a representação, via teatro, da mulher urbana, da sua posição social, da aceitação da sua presença em espaços públicos estritos, desde que supervisionada e contornada por comportamentos moralmente aceitáveis. Tal representação, como destaca Lopes, seria marcada por uma dialética entre o masculino e o feminino que, ao enfatizar as diferenças, acentua uma hierarquia: coloca, de um lado, o pai, o esposo e o irmão numa posição de autoridade e, do outro, a mãe, a esposa e a irmã, submetidas a uma tutela permanente, que não está presente apenas nos espaços privados, como a casa, mas se estende aos espaços públicos.

Em seus romances, particularmente os de caráter urbano, Alencar também propôs a discussão sobre a temática do papel mulher na sociedade brasileira do século XIX. Em Lucíola (1862), por exemplo, a nota tônica recai sobre a profunda transformação pela qual passa a personagem principal, Lúcia. Marcada por uma dualidade ${ }^{2}$, pois ao mesmo tempo em que tem seu

\footnotetext{
${ }^{2}$ Norma Telles (2000) aponta que as representações da mulher dentro do romantismo são geralmente permeadas por uma dicotomia, podendo a mulher assumir dois papéis distintos: ou "anjo do lar" ou "mulher decaída". No caso do
} 
corpo corrompido pela prostituição, mantém pura a sua alma, ela, ajudada por Paulo, aquele que a ama verdadeiramente, deixa para trás a vida de mulher independente e dona de si, que domina os salões da Corte, para se tornar uma mulher recatada e simples, vivendo afastada do centro da cidade e sendo, inclusive, sustentada por seu amado. No entanto, o passado lhe deixou marcas que não podem ser removidas, pois estão impregnadas no seu corpo. Daí o desenlace sacrificial que lhe está reservado. Só ele é capaz de desfazer a dualidade que a envolve e devolver-lhe plenamente a pureza. Também marcado por um discurso moralizante, trata-se de uma tentativa conformar comportamentos e sentimentos considerados apropriados à mulher, dentro de um contexto de mudança social, como dito anteriormente.

Essa discussão sobre o papel da mulher, circunscrita ao teatro e ao romance, retorna novamente, só que agora dentro do campo político e adquire contornos conceituais precisos. Tratase de uma temática esparsamente discutida por Alencar em dois de seus escritos políticos: Uma tese constitucional: a Princesa Imperial e o Príncipe Consorte no Conselho de Estado, publicado em 1867, e Sistema representativo, publicado um ano depois, em 1868. Ambos trazem argumentos específicos sobre a temática da participação feminina, mas que se relacionam analiticamente de maneira complementar. Assim, se o texto de 1867 parece incorrer, pura e simplesmente, na defesa da incapacidade política da mulher, o texto de 1868, como será demonstrado, aponta para inexistência política dessa categoria social como um problema a ser pensado. Ao que tudo indica, esta última acepção já seria fruto de um amadurecimento das ideias do autor.

Dessa forma, propõe-se aqui uma investigação das particularidades conceituais de José de Alencar contidas nesses dois escritos. Para tanto, o artigo se divide em duas partes: na primeira, procura se debruçar sobre o debate, os personagens e os argumentos atrelados ao texto Uma tese constitucional; na segunda, de caráter mais teórico, destaca o arcabouço conceitual de Alencar contido no Sistema Representativo, base sobre a qual ele aborda o tema da participação feminina e elabora uma via conceitual caracteristicamente sua, que alia, numa mesma matriz, elementos aparentemente contraditórios, quais sejam: participação e tutela. O pressuposto é que a empreitada analítica, além de favorecer a compreensão dos argumentos do autor em seu próprio contexto, pode também trazer elementos explicativos a respeito do Brasil de hoje, das suas fragilidades institucionais, dos valores que norteiam a conduta dos atores políticos, ajudando a dar mais um passo na construção de uma história conceitual.

\section{Pimenta Bueno, Alencar e a Princesa Imperial}

romance Lucíola de Alencar, a personagem principal Lúcia ou Maria da Glória, e o fato de apresentar os dois nomes é significativo, parece assumir os dois papéis ao mesmo tempo. 
Mesmo vindo de uma tradição familiar liberal, José de Alencar inicia sua carreira política como candidato à Câmara dos Deputados Gerais pelo Partido Conservador. Eleito para a Legislatura 1861-1863, ainda tímido na tribuna, começa a ganhar gosto pelo novo espaço de atuação. Nesse mesmo período, o cenário político se transforma com a ascensão da Liga Progressista ao governo, o que dificultaria a sua reeleição nas Legislaturas subsequentes. No entanto, ainda que fora da tribuna da Câmara, o romancista não deixou de atuar politicamente através de seus escritos, como foi o caso das Cartas de Erasmo (1865-1868). ${ }^{3}$ Nesse sentido, muito atento ao debate político travado nas Câmaras Representativas, Alencar não deixou passar em branco aquilo que considerava digno de nota.

Foi esse o caso da publicação do texto Uma tese constitucional. Trata-se de uma resposta crítica de José de Alencar ao eminente jurisconsulto do Império José Antonio Pimenta Bueno (1803-1878), o Visconde de São Vicente, que na sessão do Senado, de 28 de maio de 1867, havia proposto projeto de lei que concedia assento no Conselho de Estado ao Príncipe Consorte da Princesa Imperial. Pimenta Bueno, também conservador, já havia publicado anos antes, em 1857, livro referencial de direito constitucional intitulado Direito público brasileiro e análise da Constituição do Império. Era uma análise sistemática de alguns dos preceitos da Carta de 1824. Conhecedor das leis e decretos que, inclusive, ajudava a elaborar, pois estava no Senado desde 1853, apresentava agora projeto de lei que propunha alteração do artigo $6^{\circ}$ da lei de 23 de novembro de $1841^{4}$.

O projeto do Visconde pretendia estender a prerrogativa de assento dos Príncipes da Casa Imperial ao esposo da Princesa Imperial. Os argumentos eram de que o Príncipe Consorte teria grande interesse nos assuntos públicos, uma vez que seria o pai do futuro imperador. Além disso, seria preciso prepará-lo "para que se habilite a ser o futuro conselheiro, o mais íntimo da futura Imperatriz" (SENADO FEDERAL, 1867a, p. 38). Como a lei nada dispunha sobre o caso, Pimenta Bueno propôs a alteração do artigo $6^{\circ}$ da Lei de 23 de novembro de 1841, nos seguintes termos:

Art. $1^{\circ}$. As disposições do art. $6^{\circ}$ da lei de 23 de novembro de 1841 , relativas aos Príncipes da Casa Imperial, são aplicáveis ao Príncipe Consorte da Princesa Imperial.

\footnotetext{
${ }^{3}$ Sobre uma interpretação da atuação política de Alencar através das Cartas de Erasmo, ver Simões (2013), Erasmo, sempre Erasmo: uma interpretação do discurso conservador de José de Alencar.

${ }^{4}$ Importante lembrar que o Conselho de Estado foi instituído no Primeiro Reinado e perdurou até 1834 quando, pela reforma constitucional advinda do Ato Adicional, foi suprimido. Fruto de outro contexto, do chamado Regresso Conservador, a lei de 23 de Novembro de 1841 recriou o Conselho de Estado, colocando-o nas mesmas bases que o primeiro. Atrelado ao Poder Moderador, possuía caráter consultivo e não deliberativo. Teriam participação nele, além dos ministros do Gabinete Ministerial, seus 12 membros ordinários, nomeados pelo Imperador. Os membros permanentes deveriam ser brasileiros e maiores de 40 anos. Além disso, assim como no Senado, o cargo de conselheiro era vitalício. Nele também tinham assento o Príncipe Imperial, quer dizer, o herdeiro presuntivo do trono, por direito, assim que completasse 18 anos, e os demais Príncipes da Casa Imperial, desde que nomeados pelo Imperador.
} 
Art. $2^{\circ}$. Ficam revogadas as disposições em contrário. (SENADO FEDERAL, 1867a, p. $39)$. $^{5}$

No entanto, não se restringia a isso. A fala do Visconde no Senado também trazia disposições sobre a Princesa Imperial. Segundo ele, tanto no texto da Constituição como no da Lei de 23 de novembro, a expressão Príncipe Imperial referia-se a ambos os sexos. Nesse sentido, não fazia diferença ser príncipe ou princesa, por direito, já teria um assento no Conselho de Estado quando completasse 18 anos. Lembrar que esse dispositivo só se aplicaria ao Príncipe Imperial, quer dizer, ao herdeiro (ou herdeira) presuntivo do trono. Em suas palavras: "Segundo nossa lei fundamental, a Princesa Imperial é a mesma personalidade do Príncipe Imperial, é ele mesmo, tem todos e mesmos direitos e prerrogativas; é a mesmíssima entidade. Nós não temos, nem queremos ter a Lei Sálica" (SENADO FEDERAL, 1867a, p. 38). Sendo assim, finaliza com a seguinte conclusão: “(...) pelo que respeita à Augusta Princesa Imperial, a lei, como já disse, é clara, expressa, categórica, não demanda disposição nova, basta que o Governo passe a cumprir o seu preceito, como deve, como os grandes interesses públicos demandam” (SENADO FEDERAL, 1867a, p. 38). Enfim, apesar de o projeto apresentado por Pimenta Bueno não se referir à Princesa, em sua fala, ele conclama que, a herdeira do trono, já com 21 anos, assuma uma cadeira no Conselho de Estado, bastando para isso, o fiel cumprimento da Constituição.

Em sua primeira apreciação no Senado, o projeto sofreu duras críticas. Em primeiro lugar, quanto ao Príncipe Consorte - naquele contexto, o Conde D’Eu. Pôs-se em dúvidas sua naturalização, alegando-se que só podem ter acesso ao Conselho de Estado os cidadãos brasileiros. Quanto à Princesa Imperial, pesou o fato de ser mulher, mesmo na condição de herdeira do trono. $\mathrm{O}$ argumento seria de que, só excepcionalmente, uma mulher poderia ser governante, desde que as altas conveniências sociais assim o exigissem. Isso se aplicaria, por exemplo, à Princesa Isabel. Sendo ela a herdeira presuntiva, caber-lhe-ia assentar no trono em caso de vacância, inclusive nos casos de ausência do Imperador. No entanto, antes disso seria, no mínimo, inconveniente que ela assumisse qualquer função política. Por fim, as críticas também alegaram que, se caberia à Princesa assumir uma cadeira no Conselho de Estado, teria também por direito um assento no Senado (SENADO FEDERAL, 1867a, p. 28), pois essa também seria prerrogativa do príncipe herdeiro.

Magoado com os comentários, mas ao mesmo tempo, convicto do que propunha, Pimenta Bueno traz novamente o projeto à discussão na sessão de 10 de junho de 1867, numa tentativa de responder às críticas recebidas. Assim, discorre sobre sua proposição de aplicação fiel das disposições da Constituição concernentes à Princesa Imperial, bem como sobre o lugar do Príncipe

\footnotetext{
${ }^{5}$ Assinaram o projeto, além do Visconde de São Vicente: Francisco Gonçalves Martins (Barão de São Lourenço), Bernardo de Sousa Franco (Visconde de Sousa Franco), Francisco José Furtado, José Maria da Silva Paranhos (Visconde do Rio Branco).
} 
Consorte no Conselho de Estado - tema e conteúdo do seu projeto. Sobre este último, esclarece e defende que a qualidade de cidadão brasileiro ele já a tem, sendo adquirida pelo ato do casamento. Não sendo elemento impeditivo. Sobre assumir parte no Governo, São Vicente reafirma que o Conselho possui caráter meramente consultivo e não deliberativo, de modo que a opinião do Príncipe poderia ou não ser aceita no interior dos debates. Além disso, a alteração do artigo $6^{\circ}$ da lei de 23 de novembro de 1841, tal como proposta, colocaria, nesse caso específico, o Príncipe Consorte da Princesa Imperial na mesma categoria que os demais Príncipes da Casa Imperial, quer dizer, dependente de forma necessária da nomeação do Imperador para assumir assento no Conselho de Estado.

Sobre a Princesa Imperial, reforça a mesma interpretação anterior, de que o artigo 144 do texto constitucional aplica-se de forma indistinta, independentemente do sexo. Comparando casos semelhantes, indaga que, se “(...) entre imperador e imperatriz reinante não há diferença de poderes, direitos e prerrogativas (...)”, seria “(...) igualmente lógico que entre Príncipe Imperial e Princesa Imperial, como herdeiro do trono, não há a mínima diferença de direitos e prerrogativas” (SENADO FEDERAL, 1867b, p. 47). Sendo assim, arremata:

\footnotetext{
Ora, como à Princesa Imperial competem todas as prerrogativas que pertencem ao Príncipe Imperial, a questão reduz-se a perguntar se este tem de direito um assento no Conselho de Estado, e, como ninguém pode negar isso, segue-se, fora de dúvida, que Augusta Princesa também tem de direito um assento no Conselho de Estado, porque a lei quer e manda, e não pergunta se se trata de varão ou senhora (SENADO FEDERAL, 1867b, p. 48).
}

Pimenta Bueno não nega que existam diferenças entre os sexos, e que estas possuam certas implicações. Por exemplo, do ponto de vista do que chama de lei comum, no âmbito da vida doméstica, é o marido que detém a autoridade. Da mesma forma, a mesma lei comum impõe que existiriam certas funções que são indecorosas às mulheres, como as funções públicas. Um elemento a ser levado em conta é o fato de que o discurso do Visconde se reveste da negativa de que haja no Brasil a vigência da Lei Sálica, normativa que excluía as mulheres da sucessão ao trono. Isso é significativo pois indica o teor das concepções por trás dos argumentos. O que está em jogo não é a defesa da capacidade política da mulher, mas a excepcionalidade de o sucessor do trono de uma monarquia ser mulher e ter, necessariamente, que assumir certas funções políticas, por assim demandarem certas conveniências sociais. Nesse sentido, tanto Pimenta Bueno como seus críticos compartilham da defesa da incapacidade política da mulher. O que muda é somente a interpretação a respeito de quando a herdeira presuntiva deva se incumbir de funções políticas: se 
antes, ou somente a partir do momento em que assumisse o trono. Enfim, existiria uma diferença de aplicação do princípio, não de sentido. ${ }^{6}$

O projeto continuou em discussão ainda por algumas sessões, sendo enfim aprovado para ser remetido à Câmara dos Deputados em 17 de julho de 1867. Fruto de acalorada apuração dos argumentos, a versão final sofreu alterações em relação ao projeto inicial, ficando assim:

Art. 1. ${ }^{\circ}$ - As disposições do art. $6^{\circ}$ da lei de 23 de novembro de 1841 , relativas aos Príncipes da Casa Imperial, são aplicáveis ao Príncipe Consorte da Princesa Imperial.

Art. 2..$^{\circ}$ - As disposições do citado art. $6^{\circ}$, na parte relativa ao Príncipe Imperial, são aplicáveis à Princesa Imperial.

Art. 3..$^{\circ}$ - O casamento do Imperante ou da Princesa Imperial com estrangeiro importa para este a condição de cidadão brasileiro naturalizado. Ele prestará respectivo juramento ao Imperador.

Art. $4^{\circ}{ }^{\circ}$ - Ficam revogadas as disposições em contrário (SENADO FEDERAL, 1867c, p. 90).

Como dito anteriormente, José de Alencar estava atento ao que se passava nas Câmaras Representativas e, mesmo fora delas, entrou na discussão via imprensa. Uma semana depois da aprovação do projeto, publica folheto intitulado Uma tese constitucional: a Princesa Imperial e o Príncipe Consorte no Conselho de Estado (1867). Como se verá, sua resposta seguirá os passos já dados pelos críticos do projeto no Senado - dentre eles, Silveira da Mota. No entanto, Alencar dará contornos mais precisos ao modo como concebe a atuação da mulher nos espaços públicos, assumindo muitos dos pressupostos já presentes em seu esforço literário. No entanto, a hipótese aqui defendida é que se trataria ainda, nesse momento, de um esforço inicial de problematização da participação política da mulher, que será retomado um ano depois no livro Sistema representativo.

Ainda no calor da hora, a publicação de Uma tese constitucional revela que o debate não era travado apenas na tribuna. O próprio Alencar faz referência à existência de um interlocutor que, assim como ele, adentrava no debate via imprensa. $\mathrm{O}$ folheto era composto pela reunião de alguns artigos de jornal, publicados muito provavelmente na sequência em que ocorriam as sessões no Senado. ${ }^{7}$ A conclusão final a que chega o texto de 1867 é que o projeto do Visconde de São Vicente deveria ser impugnado por ferir preceitos constitucionais. Isso porque não seria juridicamente legal "conferir [por meio de Lei Ordinária] atribuições e direitos aos membros da família imperial, pessoas cuja condição política precisa ser definida na Carta Fundamental" (ALENCAR, 1867, p. 60). Daí tratar-se de Uma tese constitucional.

Ao longo do percurso, Alencar prolifera os argumentos contrários ao projeto, não só em relação ao Príncipe Consorte, mas fundamentalmente, para o que interessa aqui, em relação à

\footnotetext{
${ }^{6}$ Vale lembrar que em Direito público brasileiro e análise da Constituição de Império (1857), Pimenta Bueno já havia declarado a incapacidade política da mulher, reafirmando sua qualidade de cidadão inativo, ao interpretar o artigo 90 da Constituição (PIMENTA BUENO, 1857, p. 470).

${ }^{7}$ Também jornalista, ao longo da sua trajetória, Alencar contribuiu com alguns jornais da Corte, como o Jornal do Comércio, O Diário do Rio de Janeiro e O Globo.
} 
Princesa Imperial. A respeito desta, o romancista se atém a debelar os argumentos do Visconde partindo daquilo que ele considera ter sido a intenção dos legisladores, tanto do texto constitucional, como da Lei de 23 de novembro de 1841. Nesse sentido, afirma que a prerrogativa do Príncipe Imperial em ter direito a assento no Conselho de Estado é exclusivamente masculina, da mesma forma como ter cadeira no Senado. Tanto é que, segundo ele, quando a lei de 1841 foi posta em execução no ano seguinte da sua elaboração, quem estava na condição de herdeiro presuntivo era a irmã de D. Pedro II, D. Januária e que não havia passado pela cabeça dos legisladores lhe conferirem o posto de conselheira. De acordo com Alencar, "sentiriam os autores da lei a necessidade de fazer menção desta circunstância, se tivessem em mente ampliar a disposição legislativa" (ALENCAR, 1867, p. 7). Não havendo essa necessidade, fica entendido que a intenção dos autores do projeto era a de que tal prerrogativa seria de aplicação exclusivamente masculina.

Além disso, para Alencar, o que estaria por trás dessa restrição seria a existência de um código moral que impediria as mulheres de atuarem politicamente. Tal seria a lei dos costumes. Fundada e legitimada pelas distinções naturais entre os sexos, ela acabaria por instituir diferentes posições e funções entre homens e mulheres. A percepção é a de que a mulher possuiria maior fragilidade e decoro, da mesma forma que seria mais suscetível de ser levada por opiniões. Sendo assim, o lugar que lhe caberia seria o espaço privado. O homem, pelo contrário, mais inflexível e ponderado, seria mais afeiçoado às funções deliberativas. Assim, o mesmo motivo que inabilitaria a mulher ao exercício do voto, impediria a Princesa Imperial de assentar-se no Conselho de Estado ou no Senado. A condição de herdeira presuntiva não anularia a sua condição social de mulher, permanecendo, portanto, as limitações impostas pela lei dos costumes ${ }^{8}$.

Somente a existência de uma afirmação positiva expressa na lei é que poderia conferir esse direito à Princesa Imperial e Alencar parece não encontrar tal disposição nem na letra, nem no espírito da Constituição. No entanto, o veredito muda caso se tornasse Imperatriz, pois adentraria naquele princípio de excepcionalidade, mencionado anteriormente, figurado, nas palavras do romancista, como uma espécie de anomalia (ALENCAR, 1867, p. 9). Esta, já averberada explicitamente pela Carta constitucional em seu artigo 117, se justificaria pela necessidade de continuação da dinastia imperial, possibilitando o funcionamento regular do regime constitucional. Apenas nesse caso há a transposição da lei moral. É o que considera Alencar:

A lei política se refere privadamente ao homem, em que só reconhece a qualidade de cidadão. Mas o bem público exige alguma exceção à regra geral; então faz-se mister que o legislador a declare positivamente, outorgando à mulher aquela classe de direitos de que os costumes sociais de acordo com a natureza a privaram.

\footnotetext{
${ }^{8}$ Alencar defende, inclusive, que o espírito da lei constitucional traria isso em seu bojo, ao decretar no artigo 120 que o casamento da herdeira presuntiva só poderia realizar-se com a aprovação do Parlamento, quando da ausência do Imperador. O mesmo não se aplicando ao Príncipe Imperial.
} 
Assim como na esfera regulamentar uma lei facultou à mulher o cargo de professora, e na esfera constitucional os fundadores da monarquia brasileira permitiram, em falta de herdeiro varão, a sucessão antisálica; era indispensável uma declaração igual para que a princesa imperial fizesse parte do conselho de estado (ALENCAR, 1867, p. 17, grifo nosso).

De qualquer forma, Alencar também considera que a condição de Imperador independe do sexo, pois trata-se de uma personalidade singular. Em suas palavras: "é uma criatura política, uma instituição nacional, acidentalmente encarnada em uma individualidade" (ALENCAR, 1867, p. 16). Seria, portanto, impessoal, de modo que a condição natural ou social específica de cada sexo não teria de ser levada em conta.

Há ainda outro conjunto de argumentos utilizados por Alencar que se concentram no entendimento a respeito do casamento realizado entre a Princesa Imperial e o seu Príncipe Consorte. Aqui, o romancista tenta elucidar como se dariam as relações entre aspectos da vida pública e da vida privada. Primeiramente, Alencar defende que há uma incomunicabilidade de direitos, de modo que o Consorte não recebe os títulos e honras, nem mesmo a nacionalidade, da sua esposa, pelo ato de casamento. Mesmo que a Princesa ascenda ao trono, o seu Consorte só recebe o título de Imperador, por exemplo, quando se tornar pai de herdeiro presuntivo do trono (art. 120 da Constituição Imperial).

Alencar considera também que o ato de casamento tem implicações essencialmente civis e, portanto, não pode fugir da regra geral que, regulada pela lei dos costumes, impõe ao Pai, ao Esposo, o pátrio poder. Assim, se na vida pública a esposa assume uma posição de proeminência, a mais alta posição, na vida privada, no círculo da vida familiar, o poder paterno encontra-se nas mãos de seu esposo. Quando atesta isso, parece que Alencar está referindo-se diretamente a uma afirmação proferida por Pimenta Bueno no Senado, na sessão de 13 de junho:

A Princesa Imperial, quando se casa, é considerada chefe de sua família no sentido político, é ela quem nesse sentido exerce o poder paternal, e dirige a educação do príncipe Grão-Pará, há como que uma inversão da norma comum, há uma inversão das diferenças que resultam da diversidade dos sexos, porque o interesse público assim manda (SENADO FEDERAL, 1867b, p. 48).

Apesar de tratar-se de um caso de exceção, Alencar discorda que, no âmbito das relações civis, o poder paterno se encerre nas mãos da Augusta Esposa. Demonstra, inclusive, que o espírito da Constituição seria mais afeiçoado à lei social comumente reconhecida. Dessa forma, recorrendo ao artigo 130, indica que seria o Pai e não a Mãe, aquele que nomearia o tutor do Príncipe Imperial durante a sua menoridade. Tal seria uma atribuição do poder paterno. Sobre esse propósito, afirma que "a constituição brasileira, e como ela todas as constituições modernas, não criou nenhum direito civil novo para regular especialmente os casamentos dinásticos" (ALENCAR, 1867, p. 26). Nesse sentido, conclui: “A rainha é soberana de seu marido na vida pública; mas na vida social, no lar doméstico, o súdito assume o caráter de que o revestiram as leis 
divinas $^{9}$ e sociais, torna-se chefe da família" (ALENCAR, 1867, p. 8). Tentando preservar um tipo de matriz familiar, historicamente construído sobre a ideia de pátrio poder, Alencar não quer permitir que sejam introduzidas alterações naquele que deve ser o modelo mais altivo da família brasileira, a família imperial, nem que se confundam os papéis masculino e feminino no âmbito da vida privada.

Como em seus romances e peças, aqui também Alencar reafirma uma hierarquia social entre os sexos, de modo que a mulher aparece sempre tutelada, seja pelo marido, pelo irmão, ou pelo filho. Daí a sua conclusão taxativa de que a Princesa Imperial não teria assento no Conselho de Estado devido à sua condição social ou às restrições impostas pela lei dos costumes. Nesse sentido, do que foi exposto até agora, parece se tratar, pura e simplesmente, da defesa da incapacidade política da mulher. No entanto, deve-se atentar, como dito anteriormente, que o tema a respeito da participação política da mulher nos escritos de Alencar não ser resumiria a esse primeiro debate. Fato é que, um ano depois de toda essa discussão, o romancista publica o livro Sistema representativo (1868). Nele, como se verá, encontram-se desdobramentos importantes para o entendimento das nuances conceituais do autor, em especial, a tentativa de tornar a inexistência política da mulher um problema a ser pensado.

\section{Participação e tutela: o problema da inexistência política das mulheres}

O texto de 1868 é uma obra sistemática. Nele, a preocupação do romancista é conceber qual seria o bom funcionamento do sistema representativo imperial, por isso, além de uma crítica ao modo como, ao longo do século XIX, o princípio do regime foi sendo desvirtuado, propõe também uma reforma da norma eleitoral, tentando adequá-la ao que entende ser uma representação democrática. Assim, é possível encontrar em o Sistema representativo, de José de Alencar, a elaboração de uma teoria da representação proporcional, a defesa da representação das minorias, bem como a conceituação de categorias básicas de uma teoria política moderna, tais como cidadão, soberania, representação política, etc.

Nesse texto, Alencar parte daquilo que pode ser considerado uma antropologia, quer dizer, uma concepção do que venha a ser o homem. Segundo o romancista, o ser humano possuiria duas faces: uma coletiva e outra individual. Ambas se completariam, conformando o caráter propriamente humano. "Sem alguma dessas maneiras de ser, ele representaria, uma multidão ou um animal, porém não o homem" (ALENCAR, 1996, p. 25). Em outras palavras, o ser humano se constituiria na simultaneidade entre o cidadão e o indivíduo. Assim, da reunião e concorrência dos cidadãos viria a pessoa coletiva, o corpo político, da mesma forma que na liberdade ou na independência de cada um, estaria aquilo que distinguiria o ser humano dos demais.

\footnotetext{
${ }^{9}$ Sobre esse adjetivo, pesa o fato das suas fortes convicções católicas.
} 
Acompanhando essas duas faces humanas, Alencar concebe duas esferas de liberdade, uma que chama de política, e outra que chama de individual ou civil. Pode-se pensar, inclusive, que tenha havido aí uma espécie de aproximação com o texto de Benjamin Constant, A liberdade dos antigos comparada à dos modernos (1819), uma vez que o pensador francês também havia pensado em duas esferas de liberdade que seriam concomitantes. As duas acepções expressariam, ao mesmo tempo, tanto a necessidade de participação dos indivíduos nos assuntos comuns da sociedade, como o reconhecimento de cada um, daquilo que lhe é próprio, a sua individualidade, bem como uma esfera de atuação privada, a família. Por fim, há de se destacar também, que as duas esferas de liberdade são complementares, de modo que, para o autor, a ausência de uma implicaria, necessariamente, na ausência da outra.

Isso posto, o próximo passo dado por Alencar é assentar a noção de cidadania no princípio de nacionalidade. Ele afirma que nacionalidade e direito político designam a mesma coisa. Assim, considera que o voto "pertence rigorosamente a qualquer individuo que faz parte de uma nacionalidade" (ALENCAR, 1996, p. 80). É como se o voto não pudesse nunca ser uma dádiva ou concessão, sendo antes uma faculdade original e inerente ao cidadão, derivando dele todos os outros direitos, de modo que cada um teria em si mesmo uma fração da soberania nacional. Dessa forma, retirar ou mesmo atentar contra essa faculdade inerente é atentar contra o próprio caráter humano.

Desse ponto de vista, para o autor, o que garantiria e definiria o indivíduo, em primeira instância, não seria, por exemplo, a propriedade, mas sim o registro civil, a patente declaração da sua existência. Nesse caso, a nacionalidade seria a fonte para o reconhecimento de qualquer direito, seja civil, seja político. Além disso, longe de atrelar a cidadania à propriedade, como fez Locke $^{10}$ em $O$ segundo tratado sobre o governo, Alencar declarou-se um veemente crítico do censo eleitoral. A propriedade não seria elemento essencial para medir a capacidade política. $\mathrm{O}$ direito político estaria na garantia da existência social dos indivíduos e não na propriedade. Sendo assim, o direito seria um só, consubstanciado, da mesma forma que o ser humano, em duas faces, uma individual e outra coletiva.

Antes de concluirmos ser Alencar um defensor do sufrágio universal irrestrito e considerálo, portanto, defensor do voto feminino, devemos considerar que o autor também concebe certos impedimentos ao exercício do sufrágio. A própria Constituição já trazia preceito específico quanto a isso, declarando suspensos os direitos políticos por incapacidade física ou moral e por sentença condenatória de prisão (art. 8), bem como declarava excluídos do exercício do voto os menores, os "filhos famílias", os religiosos claustrais e os criados de servir, com as suas exceções, além daqueles que ficavam de fora por causa do censo (art. 91). No entanto, há de atentar para o fato de

\footnotetext{
${ }^{10}$ Importante destacar que Alencar discute alguns dos argumentos de Locke no texto A propriedade (1883), publicado postumamente.
} 
que, no interior do arcabouço de Alencar, existiria uma distinção entre o direito de voto e o direito de representação. Dessa forma, reconhecendo as incapacidades, Alencar afirma que "o sexo, a idade, a moléstia e outros impedimentos inabilitam certas pessoas para o exercício próprio ou direto da soberania", mas reconhece que tais impedimentos não privam essas pessoas do direito político que lhes é inerente, e que “(...) por seu órgão devem exercer os direitos que lhe competem" (ALENCAR, 1996, p. 80, grifo nosso).

Nesse sentido, o problema da participação política não se restringiria somente à composição de um corpo eleitoral, conformado por aqueles que são considerados aptos ao exercício do voto, mas também seria necessário reconhecer o direito político daqueles que, por algum impedimento, estariam excluídos dessa atividade - discussão muito próxima da distinção francesa entre cidadãos ativos e cidadãos passivos. Importante destacar que, em tais impedimentos, o que estaria em pauta seria a questão da dependência civil atrelada à domesticidade. Sendo assim, as mulheres, os menores e os inválidos por doença, por exemplo, uma vez que seriam civilmente dependentes, não poderiam exercer por si mesmos o direito do voto. Em outras palavras, uma vez que as liberdades, civil e política, estariam imbricadas, a ausência da primeira comprometeria necessariamente a plenitude da segunda. Enfim, não se trataria, para o autor, de superioridade ou inferioridade política ou de exclusão do direito político, visto que este é inerente a cada um, mas simplesmente de impedimentos que impossibilitariam o exercício livre e direto do voto.

Ao contrário do que possa parecer - e a exposição do primeiro debate poderia levar a esse entendimento -, José de Alencar não relegou à mulher uma incapacidade política natural, pura e simplesmente, a exemplo dos antigos. Para ele, como ente jurídico e racional, a mulher possuiria em si mesma um direito político que deveria ser levado em consideração na constituição do corpo político e na delegação da soberania nacional. Ele afirma que

a mulher, o menor, o alienado são proprietários, consumidores, contratantes, herdeiros; e em todas essas relações contribuintes do estado. As leis do país lhes interessam também; tem o princípio de origem, d'onde procede a nacionalidade; não há razão que os exclua dos direitos políticos. A incapacidade determina apenas o modo de ação, o exercício (ALENCAR, 1996, 81, grifo nosso).

Observe-se que aqui Alencar incluiu, além do menor e do louco, a mulher como parte interessada e constituinte da comunidade política. Quer dizer, o direito político que lhe é inerente não deve ser ignorado. Sendo assim, o romancista reconhece que as mulheres, quer dizer, as esposas, as mães, as filhas, as irmãs, devem exercer seu direito de participação política por seu legítimo representante (ALENCAR, 1996, p. 80). Ao que tudo indica, este deveria ser o chefe da família, o detentor do poder paterno: 
legítima representação dos direitos políticos inativos. A civilização um dia a concederá. Então essa parte da humanidade que na vida civil comunga em nossa existência, não há de ser esbulhada de toda a comunidade política; aquelas que são esposas, mães, filhas e irmãs de cidadãos, e tem senão maior, tanto interesse na sociedade como eles, não serão uma excrescência no estado. Participarão da vida política por seus órgãos legítimos; e quando assumam a direção da família na falta do chefe natural, exercerão por elas mesmas o direito de cidade, servindo de curadora ao marido ou de tutora aos filhos (ALENCAR, 1996, p. 82, grifo nosso).

Observe-se aqui que, quando Alencar fala de excrescência não está se referindo a outra coisa senão à exterioridade política da mulher, o fato de serem ignorados os seus direitos políticos inerentes, uma vez que eram consideradas politicamente incapazes. Na tentativa de resolver esse dilema, aponta que a célula familiar poderia funcionar como unidade política, reconhecendo no chefe da casa o tutor político dos incapazes, da mesma forma como já se constituía tutor civil dos menores. Seria, então, no interior dessa unidade política familiar que poderia ser concebida a participação política da mulher. Uma tentativa de conciliação entre participação e tutela, que pode ser denominada de cidadania tutelada. ${ }^{11}$

Sobre esse mesmo tema, Anne Verjus (2005), nota como no contexto da revolução de 1848, na França, a instituição do sufrágio universal masculino gerou um problema a ser resolvido: o do pertencimento das mulheres à comunidade política. A autora observa o modo como a noção de voto familiar, no interior das propostas de reforma eleitoral, trouxe consigo um caráter individualizante a respeito do sufrágio, em contraposição ao voto familiarista, fazendo com que a família fosse percebida como "um grupo social constituído por pessoas distintas, (...) cuja existência individual seria reconhecida pela atribuição de um voto suplementar ao eleitor" (VERJUS, 2005, p. 427). A autora também observa que essa mudança de percepção, mesmo tendo como pano de fundo a tônica da distinção entre os cidadãos pais de família e os cidadãos celibatários, tornou visível a exterioridade política das mulheres:

não se trata tanto de outorgar o voto às mulheres e aos filhos, mas de fazer pesar os pais de família diante dos celibatários. (...) Nesse aspecto, o fato de contar os membros da família mostra que, para uma parcela da opinião pública, foi superada sua inexistência política [das mulheres e dos filhos]: sem chegar ao ponto de fazê-los participar, formulase a questão de que eles sejam representados, como membros da sociedade" (VERJUS, 2005, p. 423).

Da mesma forma, parece que Alencar afirma que os membros da família, além do Pai, são também membros da comunidade e que, portanto, estariam interessados nela. Assim como no caso da proposta francesa do voto familiar da metade do século XIX, ao apontar que o núcleo familiar

\footnotetext{
${ }^{11}$ Em um breve exercício de análise comparativa, pode-se dizer que tal proposta de Alencar o colocaria numa posição intermediária entre duas vertentes liberais: a) a vertente lockeana (1998) que, a partir de sua delimitação antropológica de quem poderia participar do pacto político, excluiria a mulher, uma vez que estaria marcada pela dependência e; $b$ ) o liberalismo de Stuart Mill (1981) que, contemporâneo a Alencar e já conformado a uma postura antipatriarcal, concebe a participação política da mulher, livre e diretamente. Assim, a expressão cidadania tutelada comportaria a acepção específica do romancista brasileiro que, ao mesmo tempo em que aponta para a inclusão da mulher na ordem política, o faz a partir de um mecanismo caracteristicamente patriarcal e hierárquico.
} 
seria composto por membros da sociedade que devem ser levados em conta na composição do corpo político, Alencar também apontou a inexistência política das mulheres (e também do menor, do inválido, do louco), embora seus comentadores não atentem muito para esse fato. Numa postura inovadora para o seu contexto, também criticou de forma clara a exclusão destes do direito político pelo fato de não poderem exercer, por incapacidade civil, o direito do voto. Por fim, diferentemente do que ele mesmo havia apontado um ano antes, no debate a respeito da Princesa Imperial, Alencar chegou a conceber a participação política livre e direta das mulheres, mesmo que em um caso de exceção, na condição de curadoras ou tutoras.

Não se pode esquecer que estamos falando de um olhar tutelar que reproduz uma condição de desigualdade política. No entanto, tal argumentação, longe de constituir, simplesmente, uma apologia à dominação masculina, traz consigo a percepção de um processo de individualização do sufrágio. Quer dizer, do reconhecimento da existência individual da mulher como parte interessada nos assuntos públicos. Talvez a distinção e a hierarquia entre os sexos preconizada hegemonicamente por seu contexto funcionasse ainda como barreira intransponível. Daí que, ao mesmo tempo em que supôs a existência do problema da participação feminina, defendeu uma mediação conservadora entre tutela e participação que acaba por diluir o sentido de uma acepção mais democratizante de seus argumentos. No entanto, o que deve ficar claro, é que sua tentativa não deixa de ser um desdobramento a respeito da discussão do tema da igualdade política, da problematização a respeito da existência política da mulher. Processo que permaneceu institucionalmente inconcluso até as primeiras décadas do século XX.

\section{Considerações Finais}

Essa perspectiva tutelar da transposição da mulher do espaço doméstico para o espaço público é muito semelhante à elaborada por Alencar, nesse mesmo período, em relação ao tema da emancipação dos escravos. Nos dois casos, prevalece a ideia de uma transição lenta, segura e gradual, de caráter conservador. No caso do elemento servil, por exemplo, tanto em suas Cartas de Erasmo, escritas entre 1867 e 1868, bem como nos seus discursos parlamentares, em especial, os de 1870 e 1871, defendeu o que chamou de revolução social dos costumes. Um processo que demandaria um progressivo aprimoramento dos valores e das relações sociais. Crítico à proposição de uma lei que versasse sobre o tema da emancipação, Alencar argumentou que deveria ser a própria sociedade brasileira que deveria realizar, em seu interior, o processo de libertação dos escravos ${ }^{12}$. É o que afirmou em uma de suas Cartas de Erasmo, datada de 16 de julho de 1867:

\footnotetext{
${ }^{12}$ Segundo ele, o melhoramento dos costumes seria evidenciado, primeiramente, pelas relações amistosas entre senhores e escravos. Além disso, Alencar contava também com o aumento progressivo do número de manumissões.
} 
A única transição possível entre a escravidão e a liberdade é aquela que se opera nos costumes e na índole da sociedade. Esta produz efeitos salutares: adoça o cativeiro; vai lentamente transformando-o em mera servidão, até que chega a uma espécie de orfandade. O domínio do senhor se reduz então a uma tutela benéfica (ALENCAR, 18671868, p. 42, grifo nosso).

Interessante como também aqui exista a necessidade de uma tutela. Parece que a superação de certas hierarquias dependeria, em alguma medida, do seu próprio reforço. A ideia seria evitar, ao máximo, efeitos perniciosos. No caso do escravo, a parca transição para o trabalho livre ou mesmo o temor de uma revolta geral; no caso da mulher, a subversão de costumes naturalmente concebidos sob um olhar civilizatório. Para Alencar, o reconhecimento do direito de participação da mulher seria ainda uma possibilidade futura (ALENCAR, 1996, p. 82). Daí o seu esforço teórico que, para permanecer coerente com o projeto esboçado anteriormente em seus romances e em seu teatro, e coerente com seu próprio contexto, pressupôs que a passagem da mulher para o espaço público deveria ser supervisionada pelo olhar masculino.

O romancista não viveu o suficiente para ver, a partir das últimas duas décadas do século XIX, o avanço da defesa do sufrágio feminino. Reconhecido também por suas peças de teatro, encenadas no final da década de 1850, é curioso imaginar o que ele pensaria da peça $O$ voto feminino, de Josefina Álvares de Azevedo, encenada no Rio de Janeiro, em 1890. O que acharia da representação da mulher que assim se constitui a partir da participação ativa na ordem política. Pelo seu histórico, talvez tivéssemos aí, no mínimo, mais um confronto.

De qualquer forma, José de Alencar sabia que o avanço da mulher no espaço público seria inevitável. Daí a insistência em um olhar constante e tutelar sobre ela, não apenas nos seus romances e peças, mas também em seus escritos políticos. Ao longo do que foi exposto, observase como suas concepções ainda são permeadas pela percepção de uma hierarquia entre os sexos que, no entanto, não o impediu de discutir o tema da participação feminina. Além disso, é importante observar também como esse debate da década de 1860, além de esconder nuances que devem ser atentadas, permite-nos o acesso a um arsenal de ideias que rondam a mentalidade da elite política imperial na segunda metade do século XIX que, surpreendentemente, parece que ainda não foram de todo, superadas. 


\section{Referências}

ALENCAR, J. de. Uma tese constitucional: A Princesa Imperial e o Príncipe Consorte no Conselho de Estado. Rio de Janeiro: Livraria Popular, 1867.

. Obra completa. São Paulo: Editora José Aguilar LTDA, Vol. IV, 1960.

1977.

Discursos parlamentares de José de Alencar. Brasília: Câmara dos Deputados,

O sistema representativo. Ed. fac-sim. Brasília: Senado Federal, 1996.

- A propriedade. Ed. fac-sim. Brasília: Senado Federal; Conselho Editorial: Superior Tribunal de Justiça, 2004.

Cartas de Erasmo. (Organização de José Murilo de Carvalho). Rio de Janeiro: ABL, 2009.

ÁLVARES DE AZEVEDO, J. O voto feminino (1891). In. SOUTO MAIOR, V. A. Josefina Álvares de Azevedo: teatro e propaganda sufragista no Brasil do século XIX. Revista Acervo Histórico, São Paulo, n. 2, pp. 65-82, 2004.

BRASIL. Lei $n$. 234, de 23 de novembro de 1841. Disponível em: http://www.planalto.gov.br/ccivil_03/leis/LIM/LIM234.htm . Acesso em: 25 set 2015

CAMPANHOLE, A.; CAMPANHOLE, H. L. Todas as constituições do Brasil. São Paulo: Editora Atlas, 1971.

CONSTANT, B. “A igualdade dos antigos comparada à dos modernos.” Disponível em: http://www.caosmose.net/candido/unisinos/textos/benjamin.pdf. Acesso em 06 set 2010.

D’INCAO, M. Â. “Mulher e família burguesa.” In. DEL PRIORI, Mary (org.). História das mulheres no Brasil. São Paulo: Contexto, 2000.

LOCKE, J. Dois tratados sobre o governo. São Paulo: Martins Fontes, 1998.

LOPES, A. H. "O teatro de Alencar e a imaginação da sociedade brasileira." Perspectivas, São Paulo, v. 37, pp. 87-111, jan/jun 2010.

MILL, S. Considerações sobre o governo representativo. Brasília: UNB, 1981.

PATEMAN, C. O contrato sexual. São Paulo: Paz e Terra, 1993.

PIMENTA BUENO, J. A. Direito público brasileiro e análise da Constituição de Império. Rio de Janeiro: J. Villeneuve, 1857.

SENADO FEDERAL. Anais do Império. 1867a, Livro 1. Disponível em: http://www.senado.leg.br/publicacoes/anais/asp/IP_AnaisImperio.asp . Acesso em 25 set 2015.

SENADO FEDERAL. Anais do Império. 1867b, Livro 2. Disponível em: 
http://www.senado.leg.br/publicacoes/anais/asp/IP AnaisImperio.asp . Acesso em 25 set 2015.

SENADO FEDERAL. Anais do Império. 1867c, Livro 3. Disponível em: http://www.senado.leg.br/publicacoes/anais/asp/IP AnaisImperio.asp . Acesso em 25 set 2015.

SIMÕES, D. S. "Erasmo, sempre Erasmo: uma interpretação do discurso conservador de José de Alencar." Revista Tendências: Caderno de Ciências Sociais, Crato, n. 7, 2013, pp. 311-351.

TELLES, N. "Escritoras, escritas, escrituras." In. DEL PRIORI, Mary (org.). História das mulheres no Brasil. São Paulo: Contexto, 2000.

VERJUS, A. "Voto familiarista e voto familiar: contribuição para o estudo do processo de individualização das mulheres na primeira metade do século XIX." In: CANÊDO, L. B. (org.). $O$ sufrágio universal e a invenção democrática. São Paulo: Estação Liberdade, 2005. 